IX Congreso de Historiadores de América Central

San José, Costa Rica

Julio, 2008.

\title{
Maria Antonia de Pravia versus Francisco Casco: El \\ Divorcio, El Dote, y La Jurisdicción Eclesiástica En El \\ Siglo XVIII en Nicaragua Y El Estatus de Mujeres de la Aristocracia del Siglo XVIII en Nicaragua
}

\author{
Por: Pat Werner \\ Miembro Correspondiente \\ Academia de Geografía e Historia de Nicaragua \\ Ave Maria University Latin American Campus \\ San Marcos, Nicaragua \\ werner@avemaria.edu.ni \\ werner@ibw.com.ni
}


Como Gracias en Honduras, ubicado en un lugar muy remoto, el pueblo, la vieja villa de Nueva Segovia, llamada hoy Ciudad Antigua, ha ido en el centro de la historia de Nicaragua por siglos. La iglesia fue construida probablemente en la segunda mitad del siglo XVII- las tejas sacadas del techo en 1991 tenían la fecha 1679. La iglesia fue atacada y quemada parcialmente por el pirata inglés Capitán Wright en Mayo de 1676. Fue robado otra vez por una banda grande de piratas; el cirujano de la pandilla, Ravenau de Lussan, describió la iglesia y pueblo en 1688. Por 200 años fue la capital de norte de Nicaragua y fue la última población en el noreste de Nicaragua. Más tarde, fue un centro de rebeldes de Augusto Sandino. Y durante la Guerra Contra fue una zona de fuego libre: un kilómetro del pueblo los EPS mataron a cada persona encontrada y los Contra mataban a cualquier EPS que encontraron en las afueras del pueblo. En 1987 en un pueblo de tal vez 1,000 almas hubo una guarnición del EPS en la plaza en frente de su iglesia de 1,700 soldados. Y en 1993 la casa cural al lado de la iglesia fue el lugar de la reunión entre el Coronel (ahora General del Ejercito) Omar Haveslavens y el rebelde Recontra, "El Chacal”, Jose Angel Talavera, su hermano "el Chacalín”, Alex Talavera, y su hermano "Comandante Esteban”, Salvador Talavera (ahora diputado en la Asamblea Nacional). En la reunión asistida por el Cardenal Ovando y Bravo y el cura de la iglesia Padre Julio Cesar Lopez, . Haveslavens ordenó que los "Chacales, " se rindieran ya. Ellos respondieron en forma enfática que no, y Haveslavens les dio 48 horas para retirarse y después iba a ordenar a sus fuerzas especiales que cazaran a los hermanos y los mataran. Dos de los hermanos Talaveras decidieron rendirse y el tercero, Alex Talavera, hizo su último ataque por Quilalí enviando un misil RPG 7 por la parabrisas de un camión del ejercito. Quilalí, ubicado a $60 \mathrm{~km}$ al este de Ciudad Antigua es donde la Guerra estalló en 1980. Peleó su última batalla en la montaña famosa de El Chipote, en las afueras de Quilalí, refugio de Augusto Sandino, y donde Alex Talavera terminó su guerra en 1994.

Hoy día Ciudad Antigua está creciendo, con calles adoquinadas, y hay paz y cultivación de muchos frijoles. Hay pocos visitantes de turistas a la iglesia y los restos de un convento de La Merced visitado por el Obispo de Nicaragua en 1751 y el pueblo tiene mucha tranquilidad. Y nadie recuerda del litigio en 1723 entre la vecina de Nueva Segovia, Maria Antonia de Pravia en contra de su marido, Francisco Casco, por su venta de parte de su dote y el robo de su hijo. Y se ve en este caso tres fuerzas: el papel 
y la importancia del dote en el mantenimiento de riquezas entre la clase aristocrática; el problema que aunque no todos de los casamientos funcionan, el derecho español no reconocía el divorcio como un litigio ordinario civil y remedios, como el regreso de un dote vendido ilegalmente, tenían de ocupar una zona gris entre la jurisdicción civil y eclesiástica, que hizo el litigio muy complicado. Y que también ilustró la gran ambigüedad entre la iglesia y estado en tratar de remedios cuando una familia o relación entre un hombre y mujer cayó en problemas.

En 1722 o 1723 Marina Antonia de Pravia entabló una demanda de divorcio en contra de su marido, Francisco Casco. Parece que ella vivía en Nueva Segovia en el norte de Nicaragua y Casco vivía en León. El expediente nota que Pravia había pagado una dote al entrar en el matrimonio y tenían al menos un hijo menor. Parte de la dote de Pravia fue una esclava y su hija, también esclava, de ocho años de edad. El proceso legal para un divorcio en el imperio de España fue basada en las leyes de las Siete Partidas, pero también en derecho canónigo. El resultado es un proceso híbrido con el obispado del lugar la sede de la causa pero con el poder civil como la fuerza coercitiva para mandar lo sugerido por la iglesia. Hay que agregar que el proceso, como en varios lugares, no fue un proceso corto y singular, sino un proceso de más que una demanda, unida por la identidad del demandante y la demandada. Y en varios casos, los temas en litigio fueron la división de los bienes de las partes, y menos probable, la custodia de los menores del matrimonio. Y para tanto del derecho hispánico sobre la familia y que tocaba en la clase aristocrática, su base fue cementado en el derecho romano.

La ley de dote es bien compleja. El Digesto del Corpus Juris Civilis contiene un capítulo que comienza el discurso sobre la dote con tres principios:

1. La razón de la dote es permanente y de acuerdo con los deseos del otorgador. Es formado puesto que se queda por siempre con el esposo. (D. 23.3.1.) ${ }^{1}$

2. Es en el interés público que la dote de la mujer sean seguros, puesto que puedan casarse por razón de ellos. ( D.23.3.2). ${ }^{2}$

\footnotetext{
${ }^{1}$ D significa el Digesto de Justiniano, o el CJS. Dotis causa perpetua est, et cum voto eius qui dat ita contrahitur, ut semper apud maritum sit.
} 
3. El termino "dote" no se usa para casamientos que no puedan ocurrir (porque son ilegales), puesto que no puede ser la dote sin un casamiento (legal). Por eso cuando la palabra "casamiento" no es aplicable, ni tampoco se puede usar la palabra "dote".(D.23.3.3) ${ }^{3}$

La institución de la dote fue absolutamente necesaria para que funcionara la fusión de familias en el mundo viejo y no desapareció en la Europa hasta el siglo XIX y la promulgación de varios códigos legales nuevos.

Había dos formas de la dote, la dote profecticia y la dote adventicia. La dote profecticia fue otorgada por el padre de la esposa o su representante; la dote adventicia fue otorgada por cualquier otra persona, incluyendo la esposa. Cada forma tenía una característica importante: con la dote profecticia el marido tuvo que regresarlo al terminar el casamiento, por separación legal o la muerte de la esposa, en su forma original; con la dote adventicia el marido no tuvo que regresarlo al terminar la relación marital si no hubiera un contrato para hacerlo al comenzar el matrimonio. (Freier y McGinn, 76) Obviamente, esta diferencia causó muchos litigios y fue el origen en un sentido de los arreglos "pre nupciales modernos“.

La ley de dote romana tiene una historia de al menos 800 años antes que fue formulado en su forma final en la Corpus Juris Civiles .... .

Como se sabe de un estudio de las bibliotecas de abogados en Argentina en el final del siglo XVIII, la mayoría de los abogados tenía copias de al menos las Instituciones de Justiniano, que fue un libro para estudiantes en su primer año de estudios de derecho en las escuelas de derecho de Justiniano en Constantinopla y Berytus (el Beirut de hoy

\footnotetext{
${ }^{2}$ Rei publicae interest mulieres dotes salvas habere, propter quas nubere possunt

${ }^{3}$ Dotis appellatio non refertur ad ea matrimonia, quae consistere non possunt: neque enim dos sine matrimonio esse potest. Ubicumque igitur matrimonii nomen non est, nec dos est.
} 
día). Tiene en sus capítulos un resumen de la ley de dote romano. Otros abogados tenían copias del Digesto de Justiniano, la fuente mayor de derecho romano. ${ }^{4}$

La ley imperial de la Corona Española tuvo un combate con los abogados y escuelas de derecho por siglos de enseñar y utilizar la ley de España, incluyendo las leyes de las Siete Partidas, en lugar de la ley clásica romano en el CJC. Finalmente, Jordan de Asso publicó su Instituciones Del Derecho Civil de Castilla (1792(1984 en facsímile) para uso de un texto para las escuelas de derecho en España y el imperio. Jordan de Asso, escribió un sumario de la ley de dote (Jordan de Asso: 51-70) que explica la ley de dote y en esta manera se ve su similitud o identidad con la ley romana con las pocas modificaciones de las Leyes De Toro. Este fue la ley del imperio en 1723 y la ley que Pravia usó para su reclamo en contra de su marido.

La ley de la definición del matrimonio, la base legal de la dote y custodia de los menores y la definición de divorcio se encuentran el las Siete Partidas, Cuarta Partida. Una comparación entre las Partidas y derecho romano en las Instituciones, El Digesto y la Novellae rinde la conclusión que Las Partidas contienen una versión fiel a la doctrina de derecho romano de la familia, incluyendo la ley de dote y arras, la definición consaguinidad para intestatos y ab inestatos, el matrimonio, el divorcio y la herencia con una influencia mucho menor de la doctrina de la iglesia Católica (sobre la posibilidad de divorcio) y una versión fiel de la doctrina de la dote aunque en forma truncada o abreviada. ${ }^{5}$

Por ejemplo, SP4.11.2 define la dote en términos idénticos de El Digesto,l notando dos tipos diferentes, la dote profecticia y la dote adventicia, con características de la formas

\footnotetext{
${ }^{4}$ Véase por ejemplo, “Derecho Mercantil en la Colonia de Nicaragua y El Reino de Guatemala”, ponencia presentada en el Octavo Congreso de Historiadores de América Central, Antigua, Guatemala, Julio, 2006.

${ }^{5}$ La sociedad de Roma que produjo la doctrina y institución de la dote como representado en el Corpus Juris Civilis en 535 d.C, obviamente había muerto cuando Alfonso el X promulgó las Siete Partidas en Castilla en 1265 d.C. Pero a pesar de la existencia efímera de influencia visigoda en el Fuero Juzgo ( 661 d.C. del Rey visigodo Sisnando, los compiladores de Alfonso, en su Parte Cuarto, escribieron una resumen del derecho romano sobre el dote y pusieron en su Partida propia. Cambia poco y sería muy bien reconocido por un abogado romano del siglo Cinco después de Cristo. Los 32 cláusulas sobre la dote son resúmenes completas de la ley de dote romano, con casi nada quitado.
} 
romanas. $^{6}$ Y SP 4.11 .30 continúa las reglas, por la mayoría de donde va la dote cuando termina el matrimonio. ${ }^{7}$

En los siglos siguiente después de la Siete Partidas no hubo mucho cambio en la legislación sobre la familia hasta el crecimiento rápido del emperio hispánico (o castellano) hasta la muerte de Isabela. Pocos meses después Fernando convocó un cortés extraordinario en la villa de Toro, que resultó con las Leyes de Toro (1505). ${ }^{8}$ Esta obra fue la mayor modificación de la ley de la familia entre los tiempos de Alfonso X y la renovación de derecho español en la mitad del siglo XIX. Hizo ajustes, probablemente necesario por razón de la modernización de la sociedad hispánica como resultado del desarrollo causado por el establecimiento del emperio y todo que significaba. $^{9}$ Mejor dicho, las leyes de Toro no hicieron cambios sustanciales sino llenaron algunas grietas que existían en Las Partidas. Felipe II, en su cédula de promulgación de su obra maestra de derecho, su Nueva Recopilación De Las Leyes destos Reynos (1567) incorporó por referencia las Leyes de Toro y, en forma de corte y pegamento, incluyeron algunas de las Leyes de Toro en el texto de su Nueva Recopilación. $^{10}$

El expediente tocado en esta ponencia no esta completo y concierna solamente el asunto ancilario del reclamo del demandante, Maria Antonia de Pravia en contra de su marido Francisco Casco por el regreso de la esclava "mulatilla” de ocho años, su mamá, y su hijo. Por el lenguaje del gobernador de Nicaragua, Antonio Poveda de Riva Neiza, en su sentencia, se sabe que el divorcio no fue final y no se sabe más, sino su disposición de las esclavas.

\footnotetext{
${ }^{6}$ SP 4.11.2.

7 SP 4.11 .30

${ }^{8}$ El facsímile de las Leyes de Toro, con comentario del Maestro Antonio Gomez (1785) (1981).

${ }^{9}$ Se puede notar también que el derecho indiano que dominaba el imperio fue modificada por varios códigos civiles nuevos, empujado por algunos reformadores, incluyendo Andrés Bello. Véase, por ejemplo, Mirow: 97-157.

${ }^{10}$ El preámbulo de Felipe II, dice, en parte: * . . . queremos que de aqui adelante no tenga autoridad alguna, ni fe juzgue por ellas, fino folamente por las defte libro, guardado en lo que toca a las leyes de las fiete Partidas, y del Fuero, lo que por la ley de Toro esta difsuesto, y ordenamos y quedando afismifmo en fu fuerza ..." NR 2.1.6 " Mandamos, que las leyes por Nos hechas, y publicadas en la Ciudad de Toro, en fiete dias del mes de março del año de mil lquinientos y cinco años, que van eomprehenfas en EFTA Recopilación, como leyes generales en los pleytos y caufas que defpues de la dicha publicación de nuevo fe huuieren començado, o començaron y mouieren, los juezes de nuestros Reynos las guarden, y cumplan, y ejecuten en todo, fegun que en ellas, y en cada vna dellas se contiene, aunque los cafos, y negocios, fobre que los dichos pleytos fe comenñaron o fe començaran o mouieren de aquí adelante, ayan acaecido, y paffado ante que las dichas leyes fe hizieffen, y ordenaffen, excepto en los cafos que las dichas leyes de
} 
A Francisco Casco le gustaba jugar naipe con un amigo, el Capitán de la Conquista Santiago de Vidaurre, de León. Un día, Casco agarró a la esclava y a su mamá y aparentemente a su hijo. En un juego de naipe, probable un tipo de apuestas, Casco perdió el juego a favor de Vidaurre. Parece que había apostado a la esclava y a su mamá. Para pagar su deuda, Casco vendió a la esclava a Vidaurre por medio de una escritura pública. En su demanda, Pravia reclamó el regreso de la esclava y de su mamá al igual que el regreso de su hijo. La demanda fue entablada en el juzgado eclesiástico del obispado de Granada y escuchado por el Prior y Vicario General Joseph de Velasco. Lo interesante es que cuando fue necesario obtener una orden para fortalecer la voluntad del Prior, el gobernador de Nicaragua, Antonio Poveda de Riva Neiza, quien residía en Masaya, firmó las órdenes y mandos.

La demanda de Pravia sobre sus esclavas fue que Casco, en un juego de naipes en León puso a la esclava pequeña y probablemente a su madre como valor para apostar. Casco perdió el juego. Para poner su pérdida en forma legal, ejecutó una escrita pública que vendió la esclava joven al Capitán de la Conquista Santiago de Vidaurre. Bajo las leyes romanas de Dote, y sin contradicción de las leyes de Castilla, Casco fue el dueño de los bienes que había recibido de Pravia cuando se casaron. Lo que reclamaba Pravia es que Casco no tenia derecho de vender a la esclava joven a una tercera persona porque estaban con casamiento roto al principio de la demanda de divorcio. Este fue el tema del juicio seguido y el tema mayor de la sentencia del gobernador, Don Antonio Poveda.

Otros asuntos tocados incluyeron su mantenimiento. Alguien, no se sabe quien porque no aparece en el archivo, mandó que Casco pagara a Pravia cuatro reales por semana en forma de mantenimiento ${ }^{11}$. El asunto del secuestro del hijo de los dos, quejado por Pravia en sus primeros alegados, al final parece solucionado y no se ve mención jamás de eso.

\footnotetext{
${ }^{11}$ Lo que es interesante es que en ningún parte de las leyes de España conocido al autor se encuentra referencia o autoridad para mandar al hombre el deber de pagar mantenimiento a la mujer en tal forma, ni un formulario como calcular la cantidad de mantenimiento. Parece muy parecido al concepto angloingles de "alimony", o alimonio. Véase Clark, 634-654.
} 
En los alegados de Casco y Vidaurre, se ven dos tipos de respuestas. Casco alegó que la venta de la esclava joven fue una transacción no relacionada con el juego de naipes. Y Vidaurre contestó que él fue una tercera persona inocente, no relacionada con los problemas de pareja, ni conoció sobre la situación del Dote de la esclavilla, y por eso tuvo derecho pleno para continuar teniendo el derecho total de poseer la esclavilla.

El juez fue el gobernador, Antonio Poveda, y él dominaba bien las leyes del emperio. Un problema que tenía Casco y Vidaurre en su defensa es que el juego de naipes como forma de apostar fue completamente ilegal en la colonia de Nicaragua y el emperio desde hace mucho. Comenzando con el rey Fernando en 1513 los primeros gobernadores prohibieron el uso de naipes y dados para juegos de apuestas (1 CS 43, ley 15; y el gobernador Lopez de Salcedo, 1 CS 284 (1527), ley 14, gobernador Pedrarias Davila 1 CS 498(1529) ley $3^{12}$. Actualmente, los reyes de Castilla con las Partidas 7.16.10 y 7.14.6 comenzando y en 1387 los soberanos habían prohibido el juego de naipe y dados como formas de apostar, republicada en la Nueva Recopilación 8.7, que aplicaba en todas partes del emperio. Y se recuerda que una de las quejas más fuertes en contra de Hernán de Cortes en su residencia en 1528 fue que él utilizó el juego de naipe de ganar miles de pesos de sus tropas propias ${ }^{13}$. Además, hay, al comienzo de la demanda, una notación del gobernador multando a Casco con 50 pesos por haber jugado naipe, en el incidente con Vidaurre.

Después de permitir cada parte, Maria Antonia de Pravia, Francisco Casco y Santiago de Vidaurre, a hacer sus alegaciones y sus repuestas, el juez-gobernador emitió su sentencia. En tres páginas, el juez lo hizo obvio que confió en los alegados de Pravia y no en las respuestas de Casco y Vidaurre. Encontró que la venta por escritura pública fue un tipo de fraude y en contra de la ley. También encontró que la defensa de Vidaurre, que fue un partido inocente no involucrado en el divorcio de Pravia y Casco, no fue defensa y tuvo que regresar la esclavilla o pagar su equivalente en valor de 250 pesos. Después de la emisión de su sentencia, Casco no hizo nada más y Vidaurre apeló la sentencia a la Audiencia en Guatemala. Se termina el archivo.

\footnotetext{
${ }^{12}$ CS significa Colección Somoza: Documentos Para La Historia de Nicaragua.

${ }^{13}$ Véase Marks:303-333.
} 
Se puede averiguar cuatro ideas de este archivo. Primero, la relación del poder eclesiástico y poder civil, en el asunto difícil de divorcio, algo prohibido por la iglesia pero algo muy común en la vida actual, se ve complicado. La iglesia escuchó la demanda pero el poder civil lo mandaba y garantizó que las ordenes de la iglesia fueran respetados. Este necesita más estudio. Segundo, como en otros casos examinados por el autor (Cf "La Corona versus Antonio Gandulla", Revista de la Academia de Geografía e Historia de Nicaragua, Junio 2006), la calidad de los jueces y procuradores de la Corona eran de clase competente y algunos de primera clase. Claramente el gobernador-juez en este caso conocía la ley y tenía la experiencia de decidir quien hablaba la verdad y quien hizo excusas para cubrir sus actos nefastos e injustos. El resultado dictado por el gobernador juez sueña la verdad a lectores modernos.

Tercero, los asuntos que se pueden nombrar "temas de mujeres" de clase alta rodeaba sobre la definición de la pareja legitima basado en derecho romano y la ley de la protección de Dote como institución. Y un examen de la ley de Dote de 1723, basado en las leyes de las Siete Partidas, la Nueva Recopilación y las Leyes de Toro muestra que es muy parecido o idéntico de la ley de dote romano de la Corpus Juris Civiles, y las Institutos de Gayo ${ }^{14}$. Y este es, a pesar de que la sociedad romana de Roma y del emperio bizantino había desaparecido desde hace siglos. Los abogados de Alfonso X escribían lo que pasaba con el Dote en la Castilla del siglo XIII o ellos reimplantaron derecho romano en la sociedad de Castilla en el siglo XIII, quien sabe cual, uno u otro. Y cuarto, en el siglo XVIII los temas de mujeres de clase alta en asunto de la familia y sus parejas no habían cambiado mucho en los 600 años desde que promulgaron las Siete Partidas. Fue hasta la mitad del siglo XIX que España y sus viejas colonias en una forma u otra votaron algunas de las leyes de las Partidas, la Nueva Recopilación y las Leyes de Toro y adaptaron leyes más en conformidad con las tradiciones modernas de Europa. O al menos algunas de las leyes ... ${ }^{15}$

Finalmente, hay que preguntar si la decisión del gobernador juez, en mandar mantenimiento de cuatro reales por semana y el regreso de la esclavilla robado, es tan

\footnotetext{
${ }^{14}$ Véase, por ejemplo, Gordon and Robinson, Moyle, y Corral. Véase también, “Tabla Comparativa de Asuntos Especificos de Derecho De Fuentes Romanos y Hispánicos“obra ineditada por el autor, 2006.

${ }^{15}$ Véase Mirow y las reformas de leyes en España después de la muerte de Fernando VII, cf, Junco y Schubert: 26-30. Véase también el caso de la Corte Suprema de los EEUU utilizando las Siete Partidas para ajudicar un caso de derecho a las costas del mar en el estado de California, Burns: vii-xxix.
} 


\section{ay) concaso \\ D) CENTROAMERKCANO \\ D)}

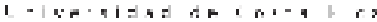

Indexaciones: Repositorio de Revistas UCR, DIALNET, Latindex, REDALYC Directorio y recolector de recursos digitales del Ministerio de Cultura de España, Directory of Open Access Journals.

Diálogos Revista Electrónica de Historia ISSN 1409- 469X. Número especial 2008. Dirección web: http://historia.fcs.ucr.ac.cr/dialogos.htm

diferente que un orden de mantenimiento y regreso de la propiedad de la mujer al terminar la relación legal con su esposo. Es muy probable que el resultado en este caso, si hubiera en hoy día, sería lo mismo, pero utilizando conceptos legales con nombres diferentes, pero con efectos idénticos. Ilustra que las necesidades de la sociedad en regular las relaciones entre hombre y mujeres llega a resultados parecidos en épocas diferentes, al menos en esto caso. 
Indexaciones: Repositorio de Revistas UCR, DIALNET, Latindex, REDALYC Directorio y recolector de recursos digitales del Ministerio de Cultura de España, Directory of Open Access Journals.

\section{Anexo: Las Firmas de Participantes en el Juicio de Pravia versus Casco}

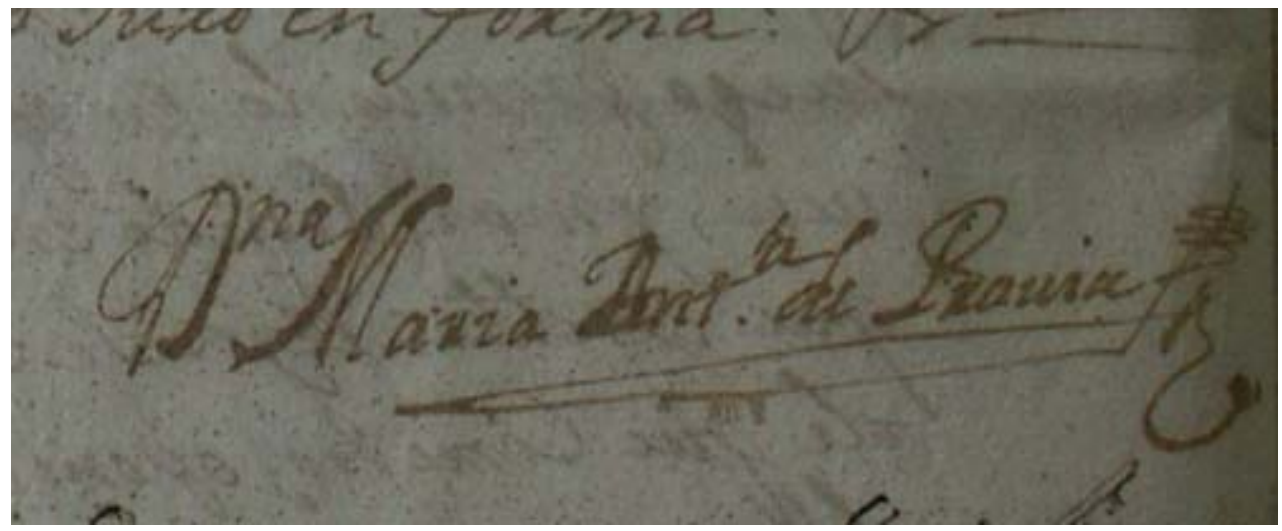

\section{Rúbrica de Maria Antonio de Pravia, Demandante}

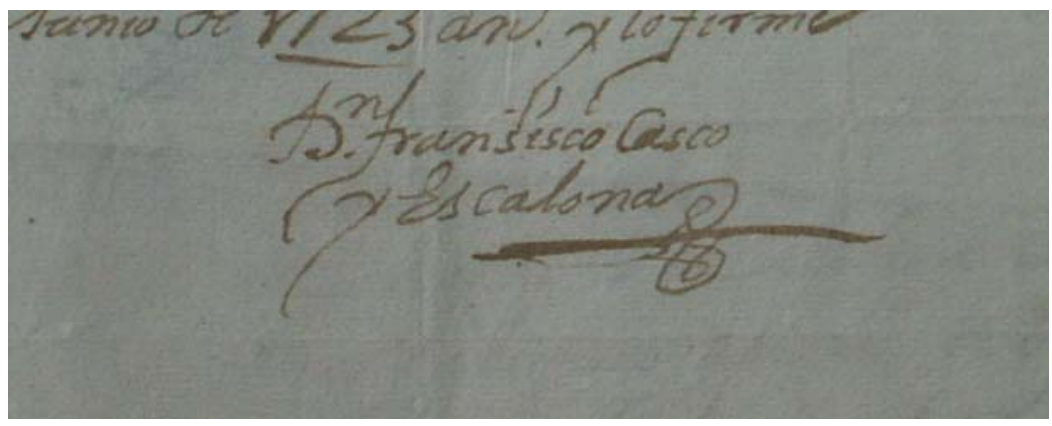

Rúbrica de Francisco Casco y Escalon, Demandado 


\section{BIBLIOGRAFIA}

AGCA (Archivos General de Centroamérica) “El Divorcio de Maria Antonia de Pravia“ ineditado, 1723.

Burns, Robert, S.J. Las Siete Partidas. University of Pennsylvania Press, Philadeophia, 5 tomos, 2004.

Clark, Homer. Cases and Problems on Domestic Relations. $2^{\text {nd }}$ Edition. West Publishing, Minneapolis, 1974.

Cuerpo de Derecho Civil Romano. (6 tomos). Barcelona, Consejo de Cientos ( 1889).

Freier, Bruce y McGinn, Thomas. A Casebook on Roman Family Law. Oxford University Press, 2004.

Gordon, W.M. y Robinson, O.F. The Institutes of Gaius. Duckworth Press, London, 1988.

Jordan de Asso. Instituciones Del Derecho Civil de Castilla. 1792 (facsímile 1984) Lex Nova, Valladolid.

Junco, Jose Alvarez y Schubert, Adrian. Spanish History Since 1808. Oxford University Press, N.Y. 2000.

Las Siete Partidas. Cortes de España. 1556 (facsímile 1985). Madrid.

Las Leyes de Toro. 1792 ( Facsímile 1985) Lex Nova, Valladolid.

Mirow, M.C. Latin American Law. University of Texas Press, Austin, 2004.

Moyla, J.B. (Traductor) The Institutes of Justinian. IndyPublishing (sin fecha).

Nichols, Barry. An Introduction to Roman Law. Clarendon Press, Oxford. 1975.

Nueva Recopilación De Las Leyes Destos Reynos. 1640. ( Facsímile 1985) Lex Nova, Valladolid.

Werner, Patrick S. "Derecho Mercantil en la Colonia de Nicaragua y Reino de Guatemala“ Ponencia presentado en el Octavo Congreso de Historiadores de América Central, Antigua, Guatemala, Julio de 2006.

Werner, Patrick S. “Tabla Comparativa De Asuntos Específicos de Derecho De Fuentes Romanos y Hispánicos“. Ineditado, 2006.

Werner, Patrick S. "La Corona Versus Antonio Gandulla”, en Revista de la Academia de Geografía y Historia de Nicaragua, Mayo 2006. 